DOI: 10.12731/2658-4034-2020-2-55-64

\title{
ОДАРЕННОСТЬ КАК ФАКТОР ВЫСОКИХ ЗНАЧЕНИЙ ПОКАЗАТЕЛЕЙ УЧЕБНОЙ УСПЕШНОСТИ СТУДЕНТОВ ВУЗА
}

\section{Ледовская Т.В.}

Ярославский государственный педагогический университет им. К.Д. Ушинского, г. Ярославль, Российская Федерация

В статье раскрываются понятия "способности», "одаренность», определены два основания для выделения психологических типов студентов: структурный и результативный показатель успешности учебной деятельности. Произведен анализ индивидуально-типологического состава студентов с разным типом успешности учебной деятельности и готовности к обучению.

Ключевые слова: способности; одаренность; успешность учебной деятельности; индивидуально-типологические особенности; студенты; типология.

\section{A TALENT AS PREDICTOR OF HIGH VALUES OF PRODUCTIVE INDICATOR OF EDUCATIONAL SUCCESS OF STUDENTS}

\author{
Ledovskaya T.V. \\ Yaroslavl State Pedagogical University named after K.D. Yshinskiy, \\ Yaroslavl, Russian Federation
}

The article deals with explanation of term «ability», "talent», two bases for allocation of psychological types of students are determined: structural and productive indicator of success of educational activities. The analysis of individual and typological structure of students with dif- 
ferent type of success of educational activities and readiness for training is made.

Keywords: ability; talent; speed of educational activity; individual and typological features; students; typology.

Проблема способностей, их понимания, познания является актуальной для отечественной и зарубежной психологии, она изучалась всегда, вне зависимости от социально-экономических условий, исторического периода. Тем не менее, до сих пор существуют споры относительно определения и соотношения понятий «способности», «одаренность», «гениальность», «интеллект» и т.д. Проблема сущности способностей и одаренности в психологии решается неоднозначно. В отечественной психологии традиционно уделяется пристальное внимание к поддержке одаренных детей в контексте их обучения в дошкольных и школьных учебных заведениях (Л.И. Ларионова, А.И. Савенков и др.). Тем не менее, успешность учебной деятельности студентов вуза, особенности проявления одаренности и специфика обучения одаренных студентов остается недостаточно изученной областью педагогической психологии.

Традиционно проблему одаренности принято начинать с анализа понятия «способности». Основные проблемы способностей представлены в работах ведущих отечественных психологов Э.А. Голубевой, Б.М. Теплова, С.Л. Рубинштейна, В.Д. Шадрикова и др. Б.М. Теплов отмечает следующее: «а) утверждается, что способности не могут быть врожденными. Врожденными могут быть только задатки, которые лежат в основе развития способностей; б) утверждается, что способности не могут возникнуть вне соответствующей деятельности» $[12$, с. 240]. Рассматривая соотношение способностей и одаренности, Б.М. Теплов поднимает важную проблему компенсации одних свойств другими и предлагает правильное ее решение: «Недостающая способность может быть в очень широких пределах компенсирована другими, высокоразвитыми у данного человека» [15, с. 21].

Интересным представляется понимание способностей В.Д. Шадрикова. Он отмечает, что «способности - свойства функциональ- 
ных систем, реализующие отдельные психические функции, которые имеют индивидуальную меру выраженности, проявляющуюся в успешности и качественном своеобразии освоения и реализации деятельности. Мера выраженности оценивается при помощи параметров - производительность, качество, надежность» [15, с. 177]. Автор показал, что «способности выступают как конкретное проявление психических функций, как свойство психологической функциональной системы, реализующей определенную психическую функцию. Следовательно, развитие способности может быть адекватно представлено как развитие системы, реализующей психическую функцию, как процесс системогенеза» [15, с. 274].

Активизация изучения концепции творческих способностей и одаренности произошла в отечественной психологии с конца 80x годов XX века (Д.Б. Богоявленая, А.М. Матюшкин, Дж. Рензулли, В.Э. Чудновский, В.С. Юркевич, М.А. Холодная, В.Д. Шадриков и др). В зарубежной научной литературе изучению различных аспектов одаренности также уделяется внимание.

В частности, в исследовании V. Koshy и C. Pinheiro-Torres говорится о необходимости профессионального развития учителей, и о том, что в рамках политики работы с одаренными обучающимися чрезмерно большое внимание уделяется выявлению одаренных и талантливых учащихся. Тогда как политика в области образования одаренных и талантливых людей была бы лучше внедрена и имела бы больший успех, если бы больше внимания было уделено разработке эффективных стратегий обучения и преподавания [4].

J.K. Ottwein указывает, что программы для выявления и работы с одарёнными учащимися не учитывают культурно, лингвистически и экономически разнообразных учащихся.

Многие учителя полагаются на предвзятое и стереотипное мышление при выдвижении кандидатов на выявление одаренных студентов. Кроме того, дефицитарное мышление и расовые установки мешают осуществлению практик культурной идентификации и реализации поликультурной педагогики, призванной выявить уникальные сильные стороны и вовлечь в процесс обучения учащихся 
с различными культурными особенностями. Поэтому автор предлагает широкий ряд рекомендация для психологов, работающих в системе образования по нивелированию стереотипного поведения при работе по выявлению одаренных обучающихся [6].

Анализ зарубежной литературы также показывает, что имеет место несколько иной подход к изучению одарённости. В частности, внимание уделяется не только одарённым детям, но и взрослым. В исследовании J.R. Cross, T.L. Cross указывается, что в работе психолога-консультанта необходимо учитывать специфические особенности одарённых взрослых. Авторы предлагают особую систему работы со взрослыми одарёнными, обращающихся с проблемами нездорового перфекционизма, тревоги, депрессии и суицидальности [1].

При работе с одаренными студентами, исследователи обращают внимание на наличие у них проблем с карьерным ростом и говорят о необходимости осуществления консультационной работы по вопросам трудоустройства и успешности в карьере [5]. Изучаются затруднения в трудоустройстве у экономически неблагополучных студентов с высокими интеллектуальными способностями [5].

Уделяется внимание изучению взаимосвязи между стрессом, совладанием и психическим здоровьем у высоко успевающих студентов. Указывается, что специфические стили совладания дифференцированно связаны с уровнем психического здоровья в группе высоко успевающих студентов. Кроме того, стили совладания (в частности, гнев и позитивная оценка) умеряют влияние стресса на глобальную удовлетворенность жизнью [7].

Изучаются психологические характеристики академически одаренных (успешных) студентов [2], однако для этого используются многофакторные личностные опросники, индивидным и субъектнодеятельностным характеристикам внимания не уделяется.

Анализ большинства концепций одаренности и творчества показывает, что авторы отмечают неповторимость каждого одаренного ребенка, но при всем индивидуальном своеобразии реальных проявлений детской одаренности существует довольно много черт, характерных для большинства одаренных детей. Причем наряду с 
глубинными, скрытыми от непрофессионального взгляда, довольно много таких, которые часто проявляются в поведении ребенка, в его общении со сверстниками и взрослыми и в познавательной и учебной деятельности. Особого внимания заслуживают те качества, которые существенно отличают одаренных детей от их сверстников, условно называемых нормальными. Знание этих особенностей необходимо для адекватного построения образовательного процесса.

В связи с этим, цель данной работы: разработка типологии студентов вуза по показателям успешности учебной деятельности для определения наиболее благоприятного типа, обладающего способностями к обучению. Естественно, что исследователей во все времена интересовали истинные предикторы высоких достижений. Разработка типологии позволяет построит индивидуальный образовательный маршрут студента и организовать индивидуальную практическую работу с каждым конкретным обучающимся. Отнесение человека к какому-либо типу выделить те качества, по которым он сравнивается с другими людьми, принадлежащими к этому типу, что помогает унифицировать ряд признаков и организовать более адресную психологическую помощь.

Теоретический анализ проблемы успешности учебной деятельности позволил понять, что наиболее полно это понятие возможно раскрыть не только при помощи показателя академической успеваемости, выраженной в10 среднем арифметическом оценок, полученных студентов в период промежуточной аттестации (сессии), но также необходимо учитывать и сформированность психологической структуры учебной деятельности (ПСДу), выраженную в индивидуальном индексе готовности к обучению в вузе (ИИГ). Выделенные показатели получили название «Результативный показатель успешности учебной деятельности» и «Структурный показатель успешности учебной деятельности», соответственно [9]. Подсчет структурного показателя успешности учебной деятельности проводился по методике «Комплексная диагностика готовности к обучению в вузе» (Н.В. Нижегородцева, Т.В. Жукова) [11].

Каждый из типов образован в результате сочетания уровней развития обоих показателей успешности учебной деятельности. В 
случае попадания студента в тип с высокими показателями успешности учебной деятельности, такой обучающийся может считаться одаренным, т.к. гармонично и высоко сочетает в своей учебной деятельности результативные и структурные характеристики.

Было доказано, что студенты с низким уровнем ИИГ имеют несформированную психологическую структуру учебной деятельности [10]. Несформированность ПСДу в этом типе обусловлена не только низким уровнем развития учебно-важных качеств, входящих в нее, но и слабыми связями этих качеств друг с другом, либо отсутствием корреляции вовсе. Отнесение индивидуального индекса готовности к обучению в вузе к диапазону больше, либо меньше среднего значения по выборке свидетельствует о том, что индивидуальное развитие учебной деятельности данного студента не вполне соответствует содержанию образования на первоначальном этапе обучения в вузе. Если уровень сформированности ПСДу выше среднего, то мы можем говорить о том, что способности и возможности таких студентов выше требований образовательной программы данного направления подготовки, а низкий уровень психологической готовности к обучению в вузе - показатель неокончательно сформированной психологической структуры учебной деятельности, что может говорить о том, у студента остро проходит адаптационный период, он использует все свои ресурсы для того, чтобы подстроиться под новые условия обучения, либо он не обладает так называемыми «учебными способностями».

Результаты статистической обработки данных исследования показали интересные результаты, которые заключаются в том, что психологическая структура учебной деятельности студентов с высоким индивидуальным индексом готовности к обучению в вузе оказывается статистически несформированной. Полученный результат объясняется тем, что, обладая высоким индивидуальным индексом готовности к обучению в вузе, студенты имеют очень индивидуальные структуры учебной деятельности, не похожие друг на друга, то есть, они имеют уникальные способности к учебной деятельности и «учебную одаренность» что на уровне группового общего статистического анализа ПСДу выразилось в ее дезинтеграции. Вместе 
с тем, это обусловливается наличием у представителей высокого ИИГ сформированного ранее уникального индивидуального стиля деятельности, который уже на начальном этапе обучения выделился из нормативно-одобренного способа деятельности. Студенты со средним ИИГ имеют оптимально сформированную ПСДу, направленную на адаптацию к началу обучения в вузе.

Таким образом, в результаты нашего исследования $[9,10]$ позволили построить следующую типологическую модель успешности учебной деятельности студентов вуза, в которой выделяются следующие категории типов: «І тип. «Высокоуспешный» тип (РП - высокий уровень, СП - высокий уровень). II тип. «Среднеуспешный» тип (РП - средний уровень, СП - средний уровень). III тип. «Низкоуспешный» тип (РП - низкий уровень, СП - низкий уровень). IV тип. «Дисгармоничный» тип. (Вариативный уровень РП и СП). Данный тип студентов характеризуется существенной внутренней неоднородностью, что позволяет выделить его подтипы: подтип студентов с высоким уровнем ВП и средним уровнем РП, подтип студентов со средним уровнем СП и высоким уровнем РП, подтип студентов со средним уровнем СП и низким уровнем РП и др.» [10, с. 21].

Исследование показало, первый тип студентов, «Высокоуспешный», можно также назвать «гармоничным», «одаренным» типом, т.к. оба показателя успешности учебной деятельности находятся на высоком уровне развития. Но, также как и при работе с одаренными детьми, такие студенты должны обучаться по индивидуальному образовательному маршруту, так как их психологическая структура учебной деятельности является индивидуальной, уникальной в связи с тем, что в обучении они используют индивидуальный стиль деятельности. Каждый студент, который относится к типу «высокоуспешного» достигает высоких показателей успешности различными способами, соответствующим целям и задачам обучения. T.e., можно сказать, что данного типа студентов менее высокая субъективная «цена» успешности учебной деятельности.

Исследование выполнено при финансовой поддержке РФФИ в рамках научного проекта № 19-29-07156 


\section{Список литературы}

1. Cross J.R., Cross T.L. Clinical and Mental Health Issues in Counseling the Gifted Individual // Journal of Counseling \& Development. 2015. Vol.93, Issue 2, pp 163-172.

2. Dixon F.A., Cross T.L., Adams C.M. Psychological characteristics of academically gifted students in a residential setting: A cluster analysis // Psychology in the Schools. 2001. Vol. 38, Issue 5, pp. 433-445.

3. Jung J.Y., Young M. Occupational/career indecision for economically disadvantaged high school students of high intellectual ability: a mixed-methods cognitive process model // Psychology in the Schools. 2017. Vol. 54, Issue 7, pp. 718-735.

4. Koshy V., Pinheiro-Torres C. 'Are we being de-gifted, Miss?' Primary school gifted and talented co-ordinators' responses to the Gifted and Talented Education Policy in England // British Educational Research Journal. 2012. Vol. 39, Issue 6, pp. 953-978.

5. Leung S.A., Conoley C.W., Scheel M.J. The Career and Educational Aspirations of Gifted High School Students: A Retrospective Study // Journal of Counseling \& Development. 1994. Vol. 72, Issue 3, pp. 298-303.

6. Ottwein J. K. Working toward equitable gifted programming: The school psychologist's role // Psychology in the Schools. Early View. 2020. Online Version of Record before inclusion in an issue. [Электронный ресурс] URL: https://doi.org/10.1002/pits.22353

7. Suldo Sh.M., Shaunessy E., Hardesty R. Relationships among stress, coping, and mental health in high-achieving high school students // Psychology in the Schools. 2008. Vol. 45, Issue 4, pp. 273-290.

8. Богоявленская Д.Б. Психология творческих способностей. М.: Академия. 2002. $320 \mathrm{c}$.

9. Ледовская Т.В. Индивидуальнотипологические особенности студентов вуза с разными показателями успешности учебной деятельности: автореф. дис. ... канд. психол. наук. Ярославль, 2010. 23 с.

10. Ледовская Т.В. Типологизация студентов вуза на основе показателей успешности учебной деятельности и готовности к обучению // Ярославский педагогический вестник. 2014. Т. 2. № 3. С. 248-251.

11. Нижегородцева Н.В. Системогенетический подход к исследованию учебной деятельности и готовности к обучению // Системогенез 
учебной и профессиональной деятельности / Под ред. проф. Ю.П. Поваренкова. Ярославль: Изд-во ЯГПУ, 2011. 323 с.

12. Общая психология: учебник для академического бакалавриата / В.Д. Шадриков, В.А. Мазилов; под ред. В.Д. Шадрикова. М.: Издательство Юрайт, 2015. 420 с.

13. Рабочая концепция одаренности [Электронный ресурс] / Д.Б. Богоявленская (ответственный редактор), В. Д. Шадриков (научный редактор), 2-е изд., расш. и перераб. М., 2003 // URL: http://psychlib. $\mathrm{ru} / \mathrm{mgppu} / \mathrm{rko} / \mathrm{rko}-001-. \mathrm{htm}$ (дата обращения 11.08.2016).

14. Рубинштейн С.Л. Проблема способностей и вопросы психологической теории // Вопросы психологии. 1960. № 3. С. 3-16.

15. Теплов Б.М. Проблемы индивидуальных различий. М., 1961. 536 с.

16. Шадриков В.Д. Способности человека. М.: Издательство «Институт практической психологи», Воронеж: НПО «МО-ДЭК», 1997. 288 с.

17. Шадриков В.Д. К новой психологической теории способностей и одаренности // Психологический журнал. 2019. том 40. № 2. С. 15-26.

\section{References}

1. Cross J.R., Cross T.L. Clinical and Mental Health Issues in Counseling the Gifted Individual // Journal of Counseling \& Development. 2015. Vol.93, Issue 2, pp. 163-172.

2. Dixon F.A., Cross T.L., Adams C.M. Psychological characteristics of academically gifted students in a residential setting: A cluster analysis // Psychology in the Schools. 2001. Vol. 38, Issue 5, pp. 433-445.

3. Jung J.Y., Young M. Occupational/career indecision for economically disadvantaged high school students of high intellectual ability: a mixed-methods cognitive process model // Psychology in the Schools. 2017. Vol. 54, Issue 7, pp. 718-735.

4. Koshy V., Pinheiro-Torres C. 'Are we being de-gifted, Miss?' Primary school gifted and talented co-ordinators' responses to the Gifted and Talented Education Policy in England // British Educational Research Journal. 2012. Vol. 39, Issue 6. Rr. 953-978.

5. Leung S.A., Conoley C.W., Scheel M.J. The Career and Educational Aspirations of Gifted High School Students: A Retrospective Study 
// Journal of Counseling \& Development. 1994. Vol. 72, Issue 3. Rr. 298-303.

6. Ottwein J.K. Working toward equitable gifted programming: The school psychologist's role // Psychology in the Schools. Early View. 2020. Online Version of Record before inclusion in an issue. [Elektronnyy resurs] URL: https://doi.org/10.1002/pits.22353

7. Suldo Sh.M., Shaunessy E., Hardesty R. Relationships among stress, coping, and mental health in high-achieving high school students // Psychology in the Schools. 2008. Vol. 45, Issue 4, pp. 273-290.

8. Bogoyavlenskaya D.B. Psikhologiya tvorcheskikh sposobnostey. M.: Akademiya. 2002. $320 \mathrm{~s}$.

9. Ledovskaya T.V. Individual'notipologicheskie osobennosti studentov vuza s raznymi pokazatelyami uspeshnosti uchebnoy deyatel'nosti : avtoref. dis. ... kand. psikhol. nauk. Yaroslavl', 2010. 23 s.

10. Ledovskaya T.V. Tipologizatsiya studentov vuza na osnove pokazateley uspeshnosti uchebnoy deyatel'nosti i gotovnosti k obucheniyu // Yaroslavskiy pedagogicheskiy vestnik. 2014. T. 2. № 3. S. 248-251.

11. Nizhegorodtseva N.V. Sistemogeneticheskiy podkhod k issledovaniyu uchebnoy deyatel'nosti i gotovnosti k obucheniyu // Sistemogenez uchebnoy i professional'noy deyatel'nosti / pod red. prof. Yu.P. Povarenkova. Yaroslavl': Izd-vo YaGPU, 2011. 323 c.

12. Obshchaya psikhologiya : uchebnik dlya akademicheskogo bakalavriata / V.D. Shadrikov, V.A. Mazilov; pod red. V.D. Shadrikova. M.: Izdatel'stvo Yurayt, 2015. $420 \mathrm{~s}$.

13. Rabochaya kontseptsiya odarennosti [Elektronnyy resurs] / D.B. Bogoyavlenskaya (otvetstvennyy redaktor), V.D. Shadrikov (nauchnyy redaktor), 2-e izd., rassh. i pererab. M., 2003 // URL: http://psychlib.ru/ mgppu/rko/rko-001-.htm (data obrashcheniya 11.08.2016).

14. Rubinshteyn S.L. Problema sposobnostey i voprosy psikhologicheskoy teorii // Voprosy psikhologii. 1960. № 3. S. 3-16.

15. Teplov B.M. Problemy individual'nykh razlichiy. M., 1961. 536 s.

16. Shadrikov V.D. Sposobnosti cheloveka. M.: Izdatel'stvo «Institut prakticheskoy psikhologi», Voronezh: NPO «MO-DEK», 1997. $288 \mathrm{~s}$.

17. Shadrikov V.D. K novoy psikhologicheskoy teorii sposobnostey i odarennosti // Psikhologicheskiy zhurnal. 2019. tom 40. № 2. S. 15-26. 